\title{
Autosomal Recessive, Fatal Infantile Hypertonic Muscular Dystrophy Among Canadian Natives
}

\author{
A.G. Lacson, S.S. Seshia, H.B. Sarnat, J. Anderson, W.R. DeGroot, A. Chudley, \\ C. Adams, H.Z. Darwish, R.B. Lowry, S. Kuhn, N.J. Lowry, L.C. Ang, E. Gibbings, \\ C.L. Trevenen, E.S. Johnson and J. Hoogstraten
}

\begin{abstract}
We describe eleven mid-western Canadian aboriginal infants with a unique, progressive muscle disorder. All except one had muscle biopsy and/or autopsy. The infants were normal newborns who rapidly developed rigidity of all skeletal muscles, with early, respiratory insufficiency. Death occurred before 18 months of age. Electromyography showed increased insertion activity and profuse fibrillation potentials; motor unit potentials and interference pattern are normal until late in the course. Pathologic features include progressive, granular to powdery Z-band transformation, myofibrillar loss, and muscle regeneration. SDS-gel electrophoresis of one muscle sample revealed increased $54 \mathrm{kDa}$ and reduced $80 \mathrm{kDa}$ protein fractions. This disease differs from other conditions with Z-band alterations because of continuous muscle activity and relentless clinical progression. The clinical features, elevated serum creatine kinase, electromyographic and muscle biopsy findings suggest a dystrophic process. The recognition of this condition as an autosomal recessive disorder allows appropriate genetic counselling.
\end{abstract}

\begin{abstract}
Résumé: Dystrophie musculaire hypertonique infantile fatale dont l'hérédité est autosomale récessive chez les autochtones. Nous décrivons onze nourrissons autochtones de l'ouest canadien atteints d'une affection musculaire progressive. Tous sauf un ont eu une biopsie musculaire et/ou une autopsie. Les nourrissons étaient normaux à la naissance. Ils ont développé rapidement de la rigidité de tous les muscles squelettiques avec une insuffisance respiratoire précoce et sont décédés avant l'âge de 18 mois. L'électromyographie a montré une activité d'insertion augmentée et des potentiels de fibrillation en abondance; les potentiels de plaques motrices et le tracé interférentiel étaient normaux jusqu'à un stade avancé de la maladie. A l'anatomopathologie, on remarque une transformation progressive de granulaires à poudreuses des bandes en $Z$, une perte neurofibrillaire et une régénération musculaire. L'électrophorèse sur gel SDS d'un échantillon musculaire a révélé une augmentation de la fraction protéique de $54 \mathrm{kD}$ et une diminution de la fraction de $80 \mathrm{kD}$. Cette maladie est différente des autres affections où l'on observe des altérations des bandes en $\mathrm{Z}$ à cause de l'activité musculaire continue et de la progression clinique inexorable. Les caractéristiques cliniques, l'élévation de la créatine-kinase, les observations électromyographiques et anatomopathologiques suggèrent qu'il s'agit d'un processus dystrophique. L'identification de cette affection comme étant une maladie autosomale récessive permet d'offrir une conseil génétique approprié.
\end{abstract}

Can. J. Neurol. Sci. 1994; $21:$ 203-212

Stiffness of skeletal muscles is an uncommon problem in infancy. We encountered eleven (11) cases with muscle stiffness, a condition until now described only in abstract form. ${ }^{1,2,3}$ Our collective experience over the last 12 years suggests that this disorder represents an uncommon but distinct, likely autosomal, recessively determined muscular dystrophy encountered among Canadian aboriginal infants along the northern regions of Manitoba and Ontario, Saskatchewan and Alberta (Figure 1). We describe the clinical, pathologic and genetic features of this disease. All patients had examination of muscle tissue either at biopsy in 8 of 10 cases or at autopsy in 6 of 10 cases. The muscle biopsies had identical features and a few subtle differences which are detailed below. At autopsy, the musculature is pale and has a firm consistency. Various muscle groups were examined. In one case, we prepared gel electrophoresis of the

From the Departments of Pathology (A.G.L., J.H.), Pediatrics and Child Health (A.G.L., S.S.S., W.R.D., A.C., C.A., J.H.), Department of Anatomy (J.A.), University of Manitoba; the Departments of Pathology (H.B.S., C.L.T.), Pediatrics and Clinical Neurosciences (H.Z.D., H.B.S., C.L.T.), and Medical Genetics (R.B.L.), University of Calgary; the Department of Pediatrics (S.K.), the Department of Pathology (E.S.J.), University of Alberta; the Departments of Pediatrics and Neurology (N.J.L.), and the Department of Pathology (L.C.A.), University of Saskatchewan; and Regina General Hospital (E.G.).

RECEIVED DECEMBER 14, 1993. ACCEPTED IN FINAL FORM JANUARY 25, 1994 Reprint requests to: Dr. A. Lacson, Department of Pathology and Laboratory Medicine. All Children's Hospital, 801 Sixth Street South, St. Petersburg, Florida USA 33731. 


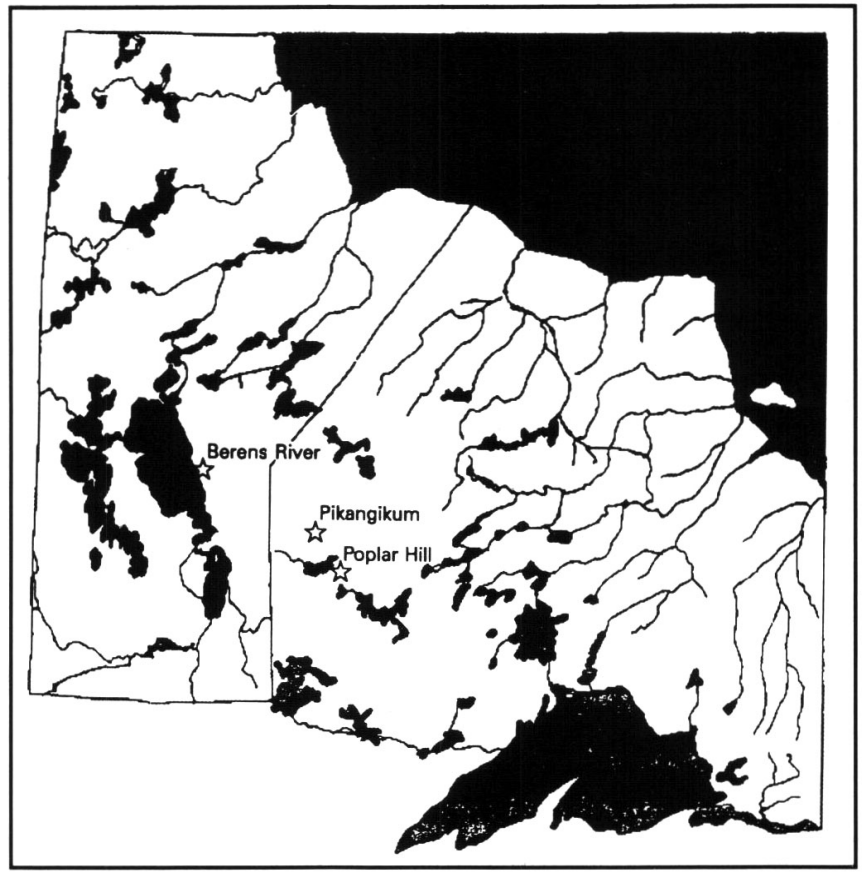

Figure 1. Details of Northeast Manitoba/Northwest Ontario map to show geographic relationships of patients 1 to 6 and 11. This map of Manitoba and Ontario marks the areas where the families of patients 1 through 11 resided. The common tribal ancestry was evident particularly among patients $1,3,4$, and 5, and among patients 9 and 10 who are cousins.

proteins isolated from fresh frozen muscle obtained at autopsy and the results are also described.

\section{REPORT OF CASES}

\section{Clinical Features}

Eleven cases seen over a period of 12 years form the basis of this report. Ten of these are pathologically confirmed. Six were seen in Manitoba, three in Alberta and one in Saskatchewan. Table 1 shows a synopsis of some essential demographic and clinical features. Details of the clinical courses of four cases illustrate the similarities and some differences that make this disease unique and separate from other forms of muscular dystrophy previously described.

\section{Patient I}

This female infant was born to a $G_{13} P_{12} S_{1} 42$ year old woman. Five siblings died under the age of two months, four from respiratory causes, having apparently been normal for the first three to six weeks of life, and one from gastroenteritis. Another sibling had died with pneumonia at four months of age. Subsequently, we learned that patient 1 was related to patients 3,4 and 5 (see Figure 4). The parents had no apparent consanguinity. In this pregnancy, hydramnios was noted. Following artificial rupture of membranes at term she was born by difficult vertex delivery, with shoulder dystocia. Her Apgar scores were 3 at one minute, 6 at five minutes, and 8 at ten minutes. In the first 48 hours, dusky spells were relieved by suction and oxygen.

She presented at seven weeks with a four-day history of respiratory distress and required assisted ventilation. Neurological examination was normal. Chest $\mathrm{X}$-ray showed patchy infiltrates in both lungs but these were insufficient to explain the need for ventilatory support. By eight weeks of age, her limb and trunk muscles felt stiff and fluoroscopy showed absence of diaphragmatic movements; electroencephalogram and CSF examination were normal. The serum creatine kinase (CK) was 1765 international units per liter (IU/1), normal values for our laboratory being less than $255 \mathrm{IU}$ for her age; both skeletal
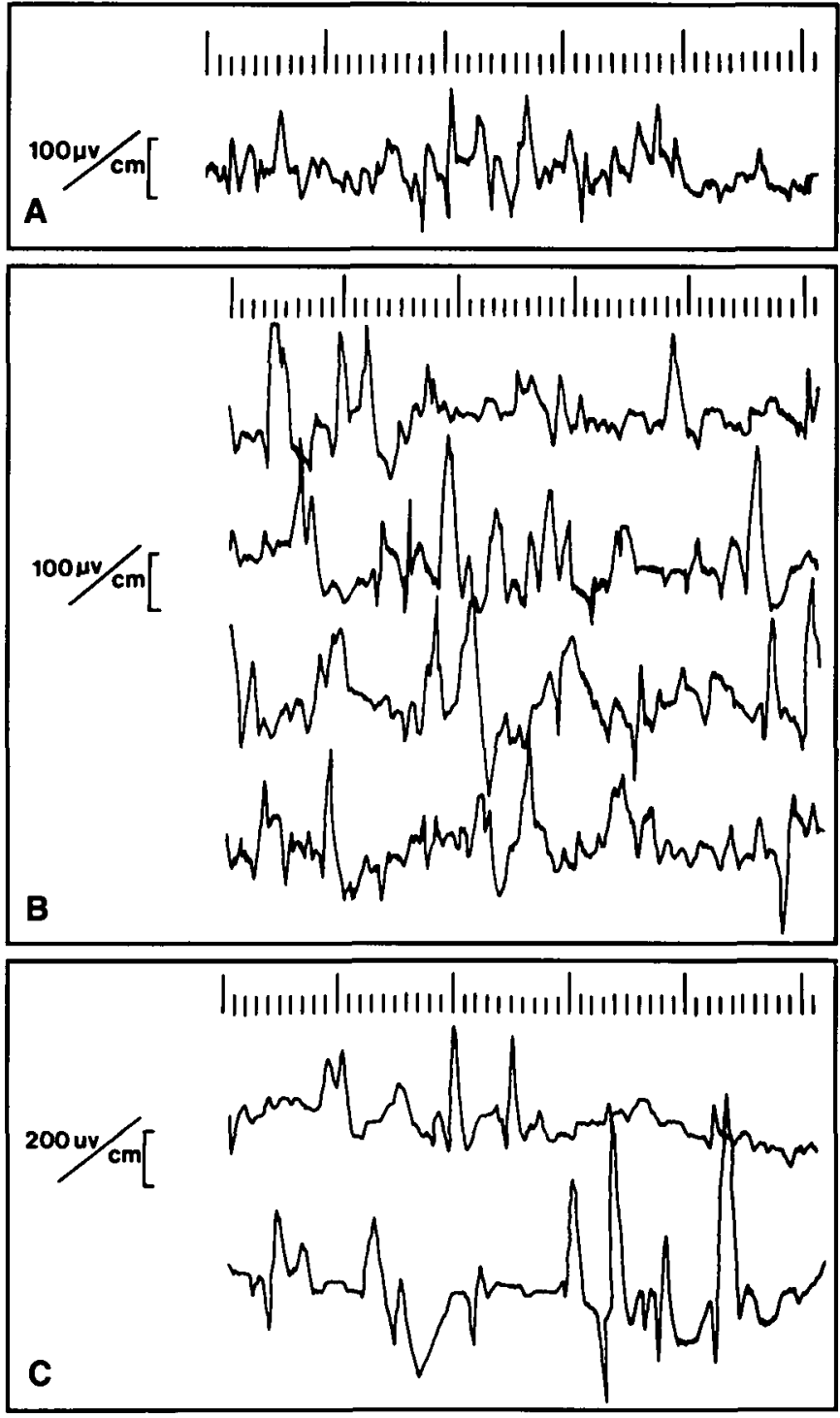

Figure 2. (A) EMG tracing from the deltoid muscle; (B) EMG tracing from the quadriceps muscle; (C) EMG tracing from the right extensor digitorum brevis. All of these tracings are from Patient I and indicate the presence of fibrillation potentials. Tracings from other patients show a similar pattern.

( $76 \%$ ), and cardiac $(24 \%)$ muscle fractions were elevated. Electromyography showed increased insertion activity and profuse (2+ to $3+$ ) fibrillation potentials in the right deltoid (Figure $2 \mathrm{~A}, \mathrm{~B}, \mathrm{C}$ ), biceps, trapezius, paraspinalis (L4) muscles. Motor unit potentials were considered normal for age. Motor nerve conduction was normal as was the muscle response to repetitive stimulation that resulted in a rise in the capillary lactate. Ketonuria was not shown after a fast of twelve to eighteen hours. A muscle biopsy was done at this time. Viral culture and serology were negative. Muscle phosphorylase, phosphofructokinase, palmityl carnitine transferase were also normal.

Over the next twenty weeks, all of her muscles that initially felt rubbery in consistency, became increasingly rigid (Figure 3 ). Voluntary movements and joint mobility became progressively decreased as did her ability to suck and swallow. Chest expansion became progressively limited because of the worsening board-like stiffness and rigidity of the trunk muscles. The serum CK values ranged from 1765 to $6050 \mathrm{IU} / \mathrm{l}$. Serial EKG's persistently showed right ventricular hypertrophy. Serial electromyographic studies continued to show profuse fibrillation potentials in all muscle groups examined; the interference pattern was 


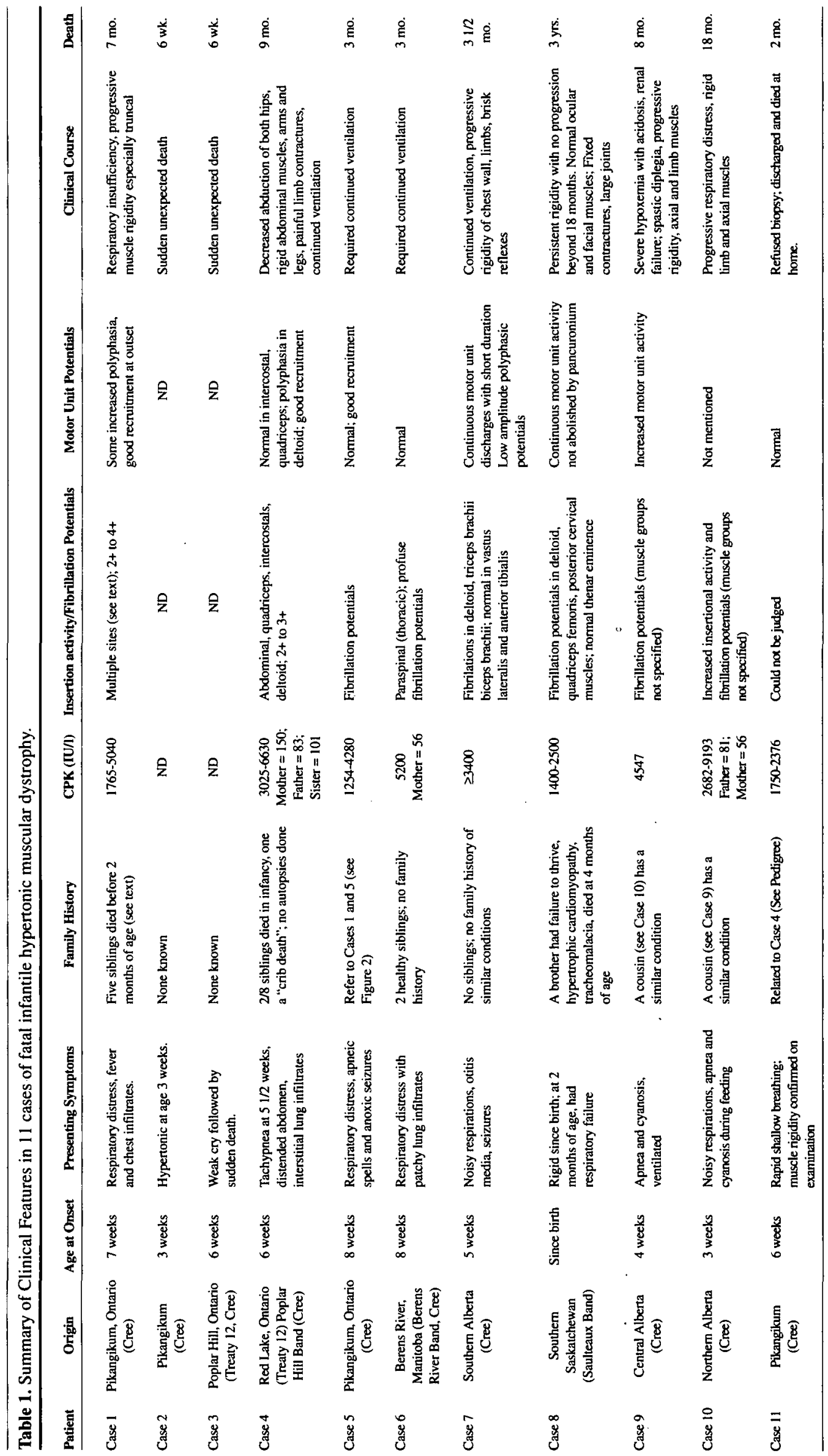




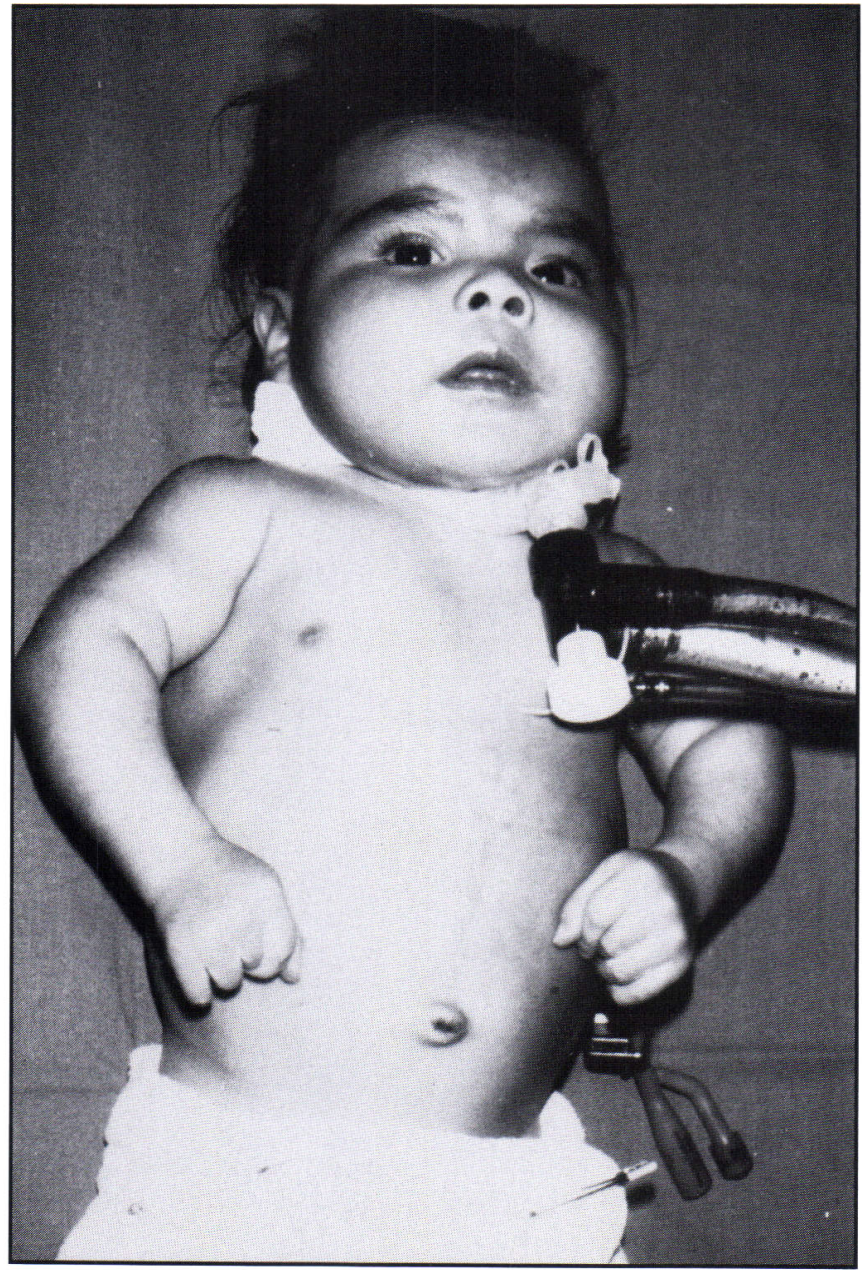

Figure 3. Patient 1 at 3 months of age; notice the clenched fists and tracheostomy on which this patient became thoroughly dependent. Contractures of the elbow are beginning to appear at this time.

initially normal for age but became reduced as her clinical state deteriorated. Nerve conduction remained normal for age. Serum myoglobin was elevated; there was myoglobinuria. Cognition, as judged by her ability to fix, follow, and give age-appropriate visual-social responses remained normal as did eye movements. There was no clinical response to Prednisone. She died of cardiac arrest at seven months of age. A complete autopsy was done.

\section{Patient 3}

This male infant was born at 39 weeks' gestation to a 21 -year-old $\mathrm{G}_{5} \mathrm{P}_{4}$ mother who had no prenatal care. The baby fed poorly and gained weight slowly; he was discharged at three weeks of age. At six weeks of age, he was brought to the city to visit relatives; while staying at his grandmother's house, he was found crying and weak, and was restless through the night before his sudden death. A complete autopsy was done. An older sibling had died suddenly at 5 weeks of age of no apparent cause. An autopsy of this sibling was not done. This patient was related to cases 1,4 , and 5 (see Figure 4).

\section{Patient 6}

This female infant was born at term by normal delivery to a $G_{3} P_{2}$ 30-year-old woman. The pregnancy was unremarkable and good fetal movements were reported. There were two normal male siblings aged 1 and 5 years. Parents were non-consanguineous and there was no family history of myopathy or myotonia. Her neonatal development was normal. She presented at age 8 weeks with respiratory difficulty for 24

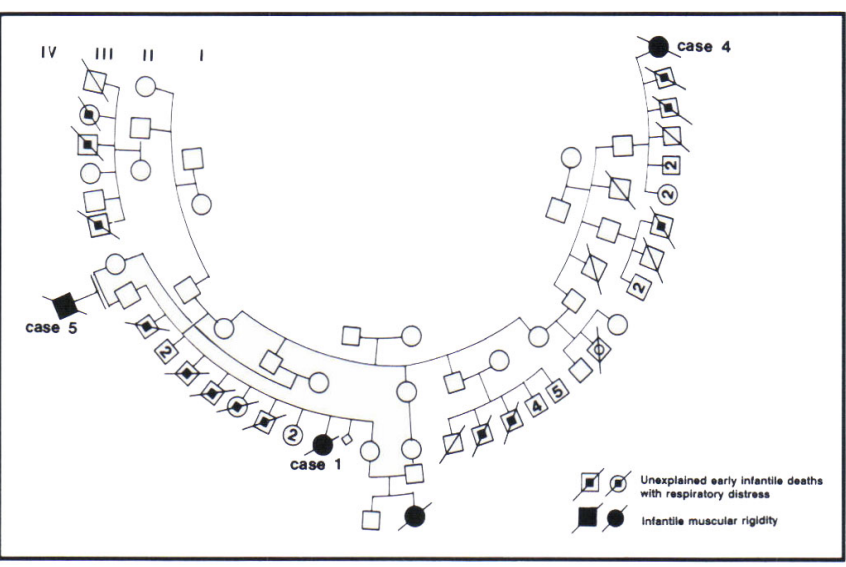

Figure 4. A pedigree to show the relationship between patients 1, 3, 4 and 5. One patient which was seen in another medical centre is also shown. Note the numerous unexplained early infantile deaths characterized by respiratory distress particularly in the family of patient 1 .

hours; this required intubation and ventilation. Chest X-ray showed patchy infiltrates. She was noted to have reduced hip abduction. On examination at 10 weeks she appeared visually alert and had good extraocular movement. Head circumference was $39.5 \mathrm{~cm}$. Paraspinal and abdominal muscles were firm and rigid, trunk rotation was reduced, and passive hip movements were limited. Tone and strength in the legs were normal. Myotactic reflexes were normal. Over a period of 4 weeks, she remained alert but developed progressive muscle rigidity, initially involving the truncal muscle groups (intercostal, abdominal and paraspinal), followed by the proximal limb muscles.

The serum CK was $5200 \mathrm{IU} / \mathrm{h}$. An EMG of deltoid, tibialis anterior and paraspinal muscles was done. Deltoid and tibialis anterior were normal. The paraspinal muscles showed increased insertional activity and profuse fibrillation potentials. Motor unit potentials were normal. Nerve conduction velocity in the peroneal nerves was normal.

She died at 3 months of age. A complete autopsy was done.

\section{Patient 9}

This female Cree infant from Central Alberta was born at term after an uncomplicated pregnancy and delivery. At two weeks of age she developed rhinorrhea and cough, which worsened and were associated with thick mucus secretions. Two weeks later she experienced an episode of apnea and cyanosis while undergoing chest $\mathrm{X}$-ray; this required emergency intubation. Collapse of the right upper lobe of the lung was shown before intubation, and atelectasis of the left lung developed after intubation. No evidence of sepsis was proved by cultures. Bronchoscopy revealed a normal tracheobronchial tree and no evidence of fistula. She deteriorated clinically and developed metabolic acidosis, acute tubular necrosis of the kidneys, hypoalbuminemia with ascites and peripheral edema, paralytic ileus, and systemic hypotension requiring dopamine support of her blood pressure. Her muscles were stiff, brawny and swollen, attributed to edema. Her acute complications were felt to be secondary to a severe systemic hypoxic insult at the time of apnea, and she eventually recovered renal and cardiovascular function. She was left with spastic diplegia, neurological function at the brainstem level without conscious awareness, and continued to be dependent upon mechanical pulmonary ventilation. Her axial and appendicular muscles became increasingly rigid.

Studies of amino acids, organic acids, glycogen homeostasis and polysaccharides were normal. The serum CK was $4500 \mathrm{IU} / \mathrm{l}$. Motor nerve conduction velocities (NCV's) were normal $(40-50 \mathrm{~m} / \mathrm{s}$ in all nerves tested). An EMG was characterized by fibrillation potentials. A deltoid muscle biopsy was done at 4 months of age.

The parents were in good health. An 8-year-old sister and a 6-yearold brother were also normal and healthy. A cousin of this infant developed generalized muscular rigidity and respiratory failure in the newborn period (Patient 10; see Table) 


\section{Pathological Findings}

\section{Light Microscopy}

The biopsies done at an early age were characterized by mild fibre size variation with few structural changes and slight interstitial inflammatory and fibrous reaction. The earliest histologic change to myofibre structure consisted of tiny, irregular, intensely eosinophilic, refractile, oval to elongated intrasarcoplasmic droplets 2-6 $\mu$ in diameter that highly resembled Zdisc streaming in as few as $10 \%$ of fibres. These were seen as pink smudges on H\&E sections, but stained bright red with the modified Gomori trichrome preparations (Figure 5A). On longitudinal, semi-thin, epon-embedded sections, they were homogenous bodies that interrupted the myofibril bundles and often caused segmental swelling (Figure 5B). Phase contrast

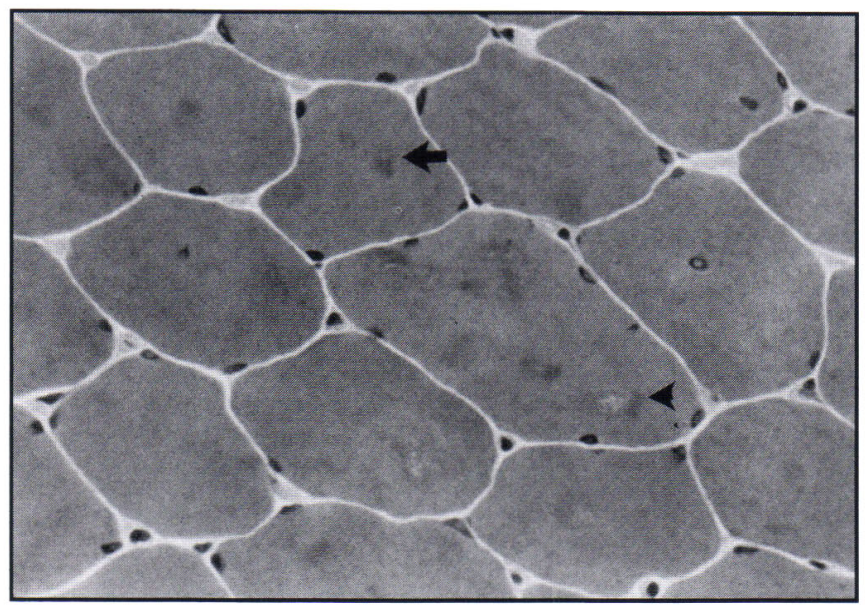

Figure 5A. Cross-section of muscle biopsy (Patient 6) with moderate variation in fibre size. Notice the presence of single to multiple hyalin inclusions resembling cytoplasmic bodies within the central areas of the sarcoplasm (arrows). A few are associated with vacuole formation (arrowhead, Modified Gomori Trichrome, x400, original magnification).

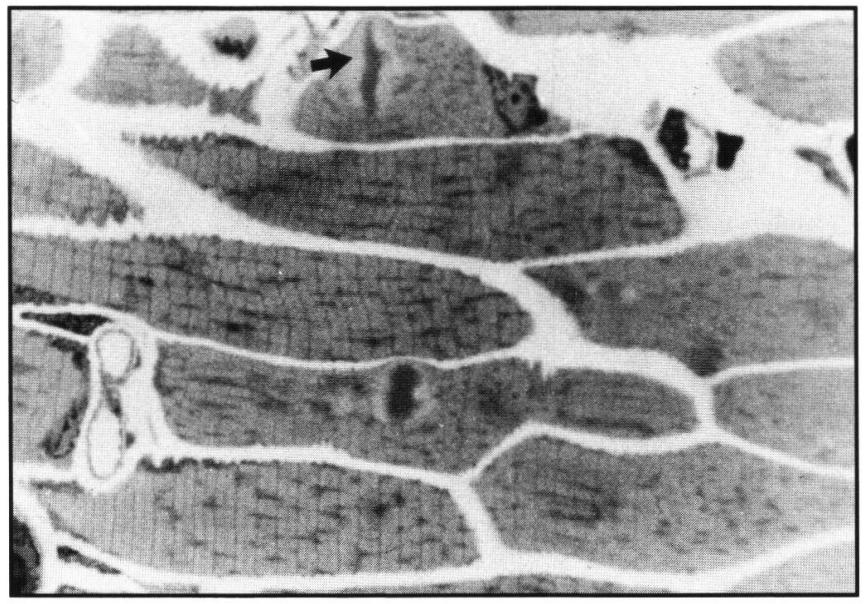

Figure 5B. Epon-embedded section of longitudinally oriented muscle fibres from patient 6 . Notice the eosinophilic, homogeneous, dense bodies some with peripheral halos, interrupting the myofibrils. The material seems to coalesce (arrow) producing serpiginous outlines across the fibre diameter (Toluidine blue, x1000, original magnification). microscopy brought out some resemblance to Z-band streaming; these were finely dispersed as strands of dark material. The number of these refractile inclusions varied from one fibre to another and from one fascicle to another within the same biopsy. In some fibres, the inclusions apparently coalesced to produce serpiginous outlines within the fibres. In a longitudinal orientation, the myofibres showed involvement at different levels along its length; the resemblance to streaming became less evident and the involved fibres underwent progressive hyalinization with loss of sarcoplasmic detail. At this stage on cross sections, the abnormal fibre contained central flocculent masses with multifocal central pallor and loss of mitochondria resembling multicores on NADH-TR stain. Later, the fibres underwent necrosis and became surrounded by phagocytic cells that formed a rim of nuclei underneath and surrounding the

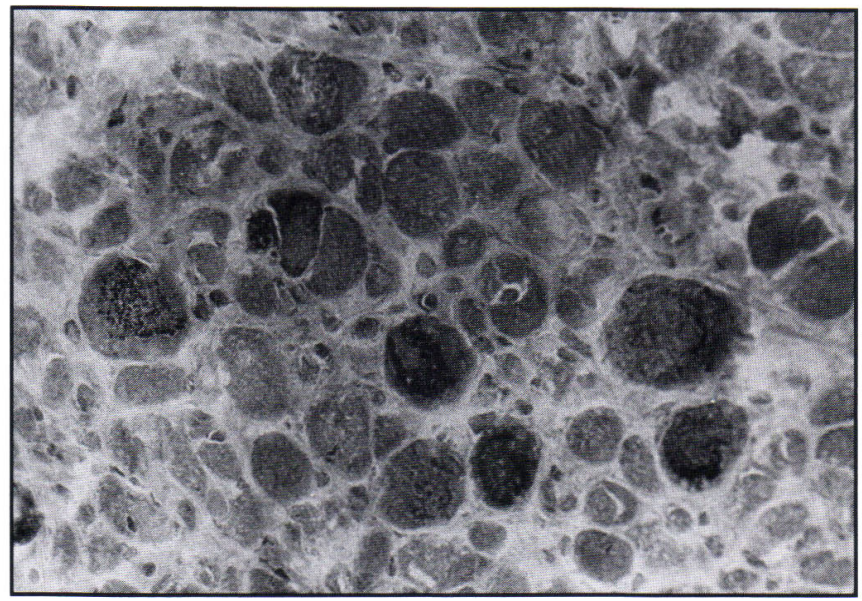

Figure 5C. (Patient 6, post-mortem muscle) Notice the marked variation in fibre size; many small basophilic fibres have large nuclei suggesting regenerative activity. Endomysial fibrosis with "myopathic grouping" is evident as well ( $H \& E, x 250$ original magnification).

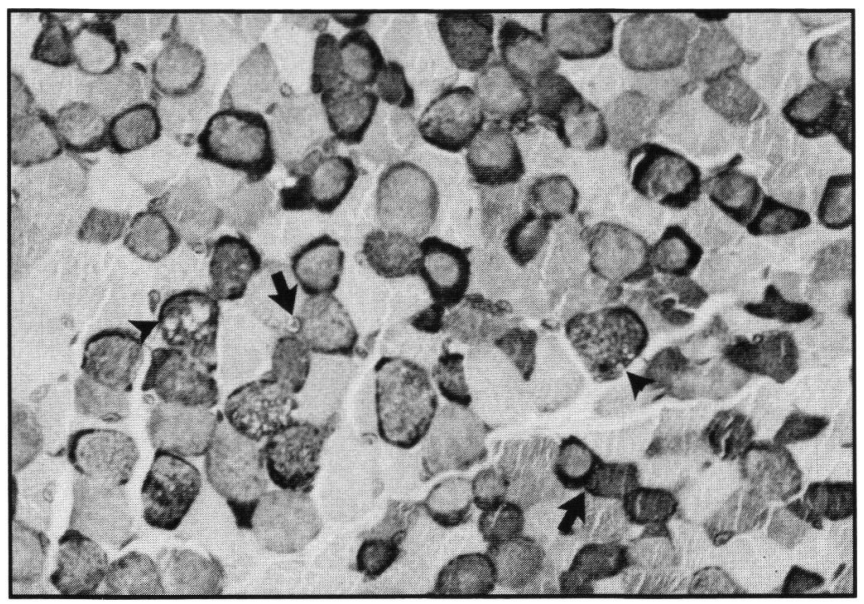

Figure 5D. Increased desmin is distributed at the periphery of the affected fibres. Note the apparent selectivity in staining; some apparently normal fibres show insignificant amount of desmin. Some fibres have enlarged nuclei with prominent nucleoli (arrows) while others have pronounced sarcoplasmic vacuolation (arrowheads). (Desmin $M A b, A B C$ technique, xl00, original magnification). 
sarcolemma. Endomysial connective tissue increased and as this became more pronounced, collagen surrounded the individual necrotic or apparently intact fibres (Figure 5C). In some cases, we found a variable number of rounded, darkly stained hypercontracted fibres, fibre splitting and central nuclei with random atrophy and hypertrophy. No fibre type grouping was seen. The PAS stains showed a few fibres with subsarcolemmal humps of glycogen whose intense staining was abolished by pretreatment with diastase. Intramuscular nerves and muscle spindles consistently showed no abnormalities. Immunohistochemistry showed intense desmin staining at the periphery of the abnormal fibres (Figure 5D) with paucity of staining in the centre. A similar pattern was obtained with vimentin staining. On longitudinal sections, the involved Z-band regions also showed a paucity of desmin compared to adjacent uninvolved sarcomeres. Acridine orange fluorochrome staining showed scattered fibres with increased RNA content, consistent with regeneration. However, the number of fibres with increased desmin far exceeded the number of these regenerating myofibres. Dystrophin staining was sarcolemmal and distinctly positive compared to a known case of Duchenne muscular dystrophy (not shown). Nitroblue tetrazolium in the presence of menadione failed to stain the inclusions (Patient 6).

Autopsy material (Patients 1, 2, 3, 5 and 6) showed that all axial and limb muscles sampled (Table 1) were involved by the same process. The most severe changes, however, were seen in the diaphragm, intercostal, and abdominal muscles. The pelvic, paraspinal, biceps, deltoid, quadriceps, gastrocnemius, and neck strap muscles were less involved. The eye muscles were not examined but these were not clinically involved. Brain and spinal cord were examined closely; apart from acute hypoxicischemic insults, no specific abnormalities were noted. The heart muscles (Patients 1, 2, 3 and 6) showed no significant histologic changes.

\section{Electron Microscopy}

A punctate to powdery transformation of a Z-band within one sarcomere was seen in the earliest lesion (Figure 6A). The granules measured no larger than 50 - 80 nanometers with thin filaments radiating outward. The change later involved the Zband of adjacent myofibrils and still later, the Z-bands of adjacent sarcomeres. Longitudinal sections showed that the change also occurred irregularly or sporadically, over the entire length of the involved fibre (Figure 6B). Where transformation had occurred over two to three sarcomeres and several myofibril groups, the fibre became distorted, and the intact sarcomeres on either side of the lesion became out of register with the adjacent uninvolved myofibrils. In autopsy material and biopsies done at several months of age, many fibres showed advanced degeneration such that all sarcoplasmic details were absent in the cross sectional area. Collagen increased progressively within the endomysial and perimysial compartment. In three biopsies, (patients 6,9 and 10) subsarcolemmal PAS positive material was unusually prominent; several crescentic accumulations of normal B-glycogen particles were seen. Apart from eccentric aggregations of sarcoplasmic masses, no specific architectural changes of subcellular organelles were noted. Focal nuclear enlargement with prominent nucleoli were interpreted as regenerative. In patient 9 , intranuclear dense paracrystalline inclusions were present, with a lattice-like pattern that resembled sarcoplasmic, Z-band-derived nemaline rods. Patients 1 and 6 had occasional tubulo-fibrillar inclusion within some welldeveloped Z-band lesions; these resembled viral elements (Figure 6C). Similar inclusions were seen in a few myonuclei of the same case. A variable accumulation of lipid within the fibres and the endomysium were also seen. The basal laminae were often redundant, and occasionally reduplicated. In late stages, the necrotic muscle fibre were invaded by phagocytic cells (Figure 6D); all sarcoplasmic detail was lost and the fibre became a sac of electron dense granules phagocytized by macrophages. The intramuscular nerves and myelin sheaths showed no abnormalities; the axons and Schwann cells are intact. Muscle spindles appeared normal. The neuromuscular junctions had normal vesicle-bearing presynaptic axon and basement membrane-lined postsynaptic clefts.

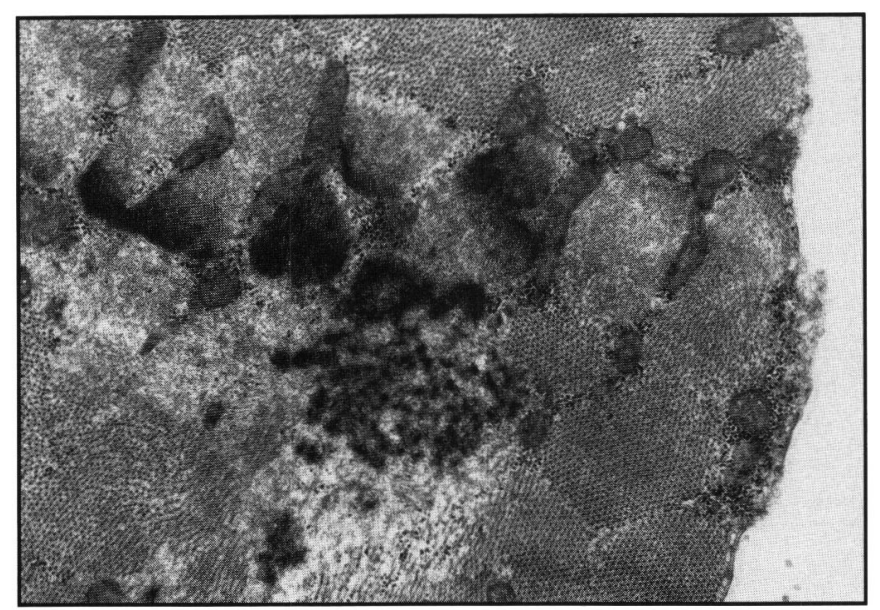

Figure 6A. An early lesion characterized by accumulation of darkly stained, powdery material with electron density of Z-bands on cross section (Uranyl-acetate, $x 2100$ original magnification).

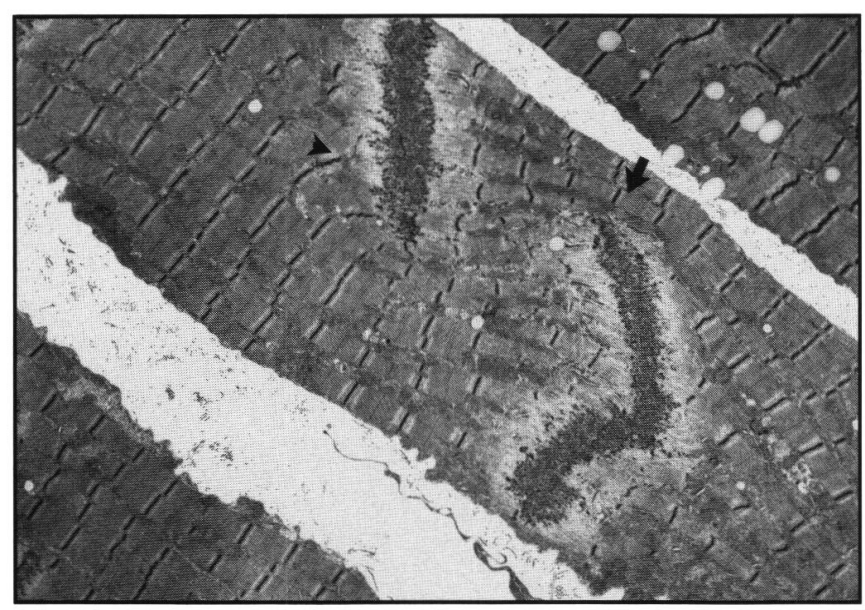

Figure 6B. (Patient 6) Longitudinal section of muscle to show two affected segments involving sarcomeres on each side of the fibre. Note the replacement of fibres by electron dense granules seemingly originating from the Z-bands. The adjacent uninvolved sarcomeres are displaced to one side (arrow) in one segment, and those above (or below) appear to be drawn into the granular area (arrowhead) (Uranyl acetate, $x 2100$, original magnification). 
Heart muscles were free of sarcoplasmic lesions. The intercalated discs were well-preserved and the usual branching pattern of myofibrillar bundles was maintained. The central nervous system was examined in 8 patients with particular attention to motor areas including the cerebral cortex, basal ganglia, thalamus and subthalamic nuclei, substantia nigra, cranial nerve nuclei and anterior horn cells. These were essentially unremarkable. There were no lesions seen in the corticospinal projection fibres throughout their course. All motor nerve roots and multiple samples of peripheral nerves including the brachial and lumbosacral plexus were unremarkable.

\section{Biochemical Study (Gel electrophoresis)}

Quadriceps femoris from Patient 6 were kept frozen at minus $70^{\circ} \mathrm{C}$ until analysis could be done. Frozen specimens of this patient and two non-related patients without neuromuscular

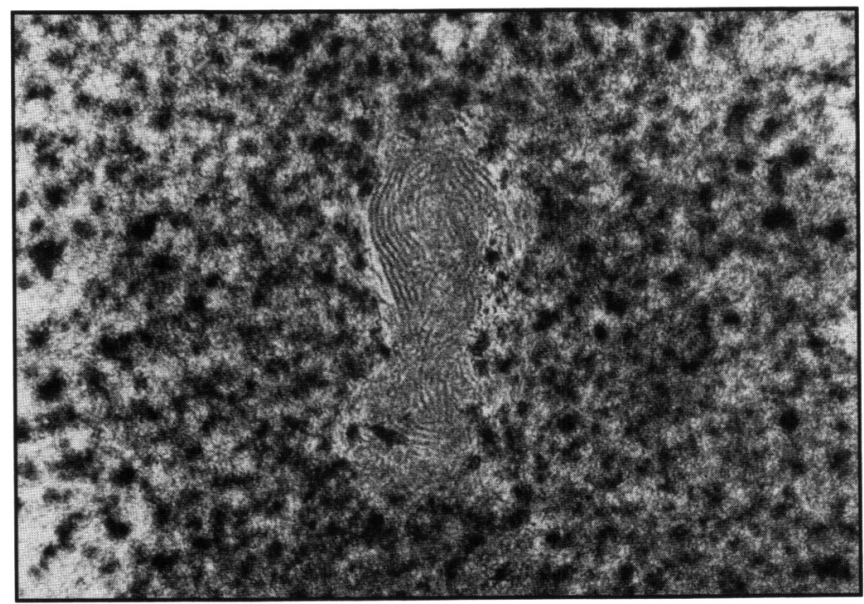

Figure 6C. (Patient I) Note the presence of striated, filamentous, virallike inclusions in the midst of the granular material (Uranyl acetate. $x 3200$, original magnification).

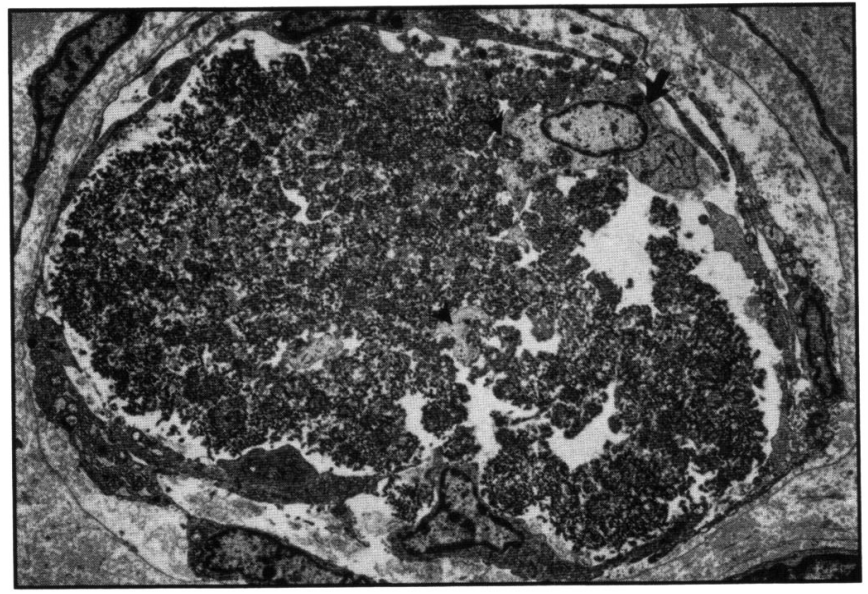

Figure 6D. Advanced degeneration in a cross-sectioned muscle fibre; granular material predominates, obscuring the myofibrillar architecture. Notice the influx of phagocytic cells with processes (arrows) insinuating between the sarcoplasmic debris and actively phagocytizing granular debris (arrowheads). (Uranyl-acetate, x2300, original magnification). disease were prepared for SDS-polyacrylamide gel electrophoresis. According to standard protocols, ${ }^{4}$ equal tissue weights of muscle were homogenized over ice for 3 intervals of $10 \mathrm{sec}$. Soluble and insoluble fractions were prepared to a final protein concentration of $130 \mu \mathrm{g} / 100 \mu 1$ and denatured for $3 \mathrm{~min}$ at $95^{\circ} \mathrm{C}$ under reducing conditions.

Samples ( $50 \mu 1$ volume) were loaded onto $10 \%$ polyacrylamide SDS-gels containing $2.5 \%$ bisacrylamide 4.5 along with high and low molecular weight standards (BioRad). The gel was run at $230 \mathrm{~V}$ for $1 \mathrm{hr}$ through the stacking gel, and $80 \mathrm{~V}$ overnight or until the bromphenol blue reached $1 \mathrm{~cm}$ above the bottom of the running gel. All gels were stained in Coomassie Brilliant Blue R250, and destained in 5.0\% methanol, 7.5\% acetic acid solution to visualize bands. After drying, the gels were mounted and scanned by transmitted light to CCD camera (Cohu 4815-5000, Infrascan, Richmond BC) attached to a microcomputer using a linear densitometer program (JAVA, Jandel, CA). On each gel, three scans per lane were averaged over duplicate lanes for each sample and for low and high molecular weight standards, and plotted against distance (mm).

\section{ReSUlts}

Figure 7 shows a typical gel of the three muscle samples run beside molecular weight standards. Bands of $100,80,42 \mathrm{kDa}$, and a pair of bands at 22 and $24 \mathrm{kDa}$ were reduced or absent from the gel or densitometric scan (not shown) of the proband muscle sample when it was compared to either normal muscle. A band at $10 \mathrm{kDa}$, which was not visible in normal samples, was present in the proband muscle, likely due to protein degradation present in that sample. The same profile of changes was apparent after normalizing scan density to the actin peak density.

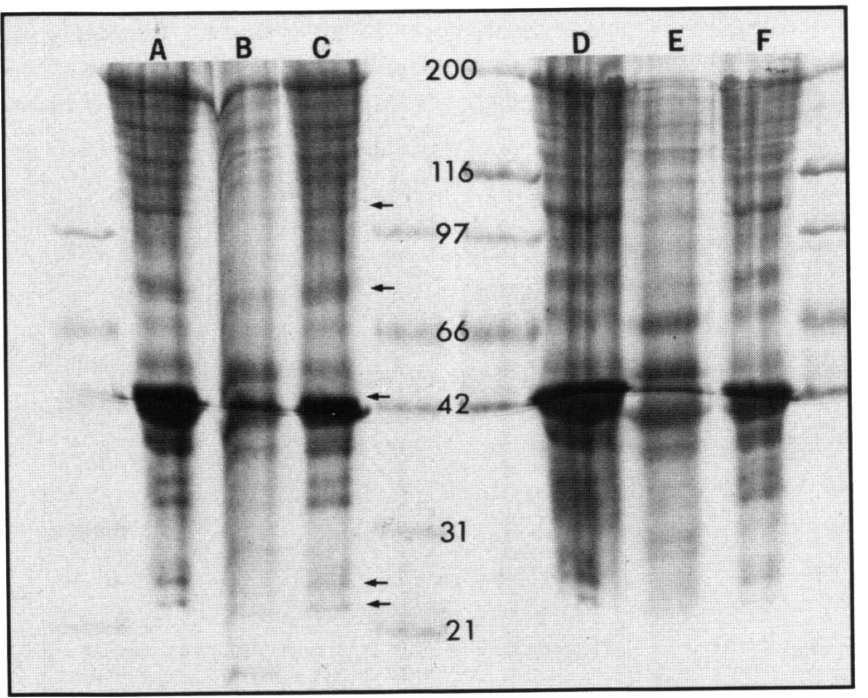

Figure 7. SDS-PAGE of muscle homogenates from Patient 6 (lane) and two age-matched normal controls. Lanes $A, C, D$ and $F$ are from normal muscles, while lanes $B$ and $E$ are from the muscle biopsy of Patient 6 . Lane $B$ contains the soluble extract and lane $E$ contains the insoluble extract. Molecular weight markers are as indicated in the center. Notice the reduced protein bands at 100, 80,42, and $22 \mathrm{kDa}$ (small arrows) in both Lanes $B$ and $E$; these bands are present in all control muscles. 


\section{Discussion}

The children described in this report were seen by clinicians at four different medical centers in Central and Western Canada. The clinical course was uniform in all but two patients (patients 2 \& 3) who presented with "sudden infant death", in our series. All but one (patient 8 ) of them were apparently normal at birth; most presented in infancy with respiratory insufficiency. The respiratory insufficiency could not be explained based solely on the clinical or radiological findings in the lungs. The stiffness characteristic of the disorder, generally became apparent some weeks later; limb and trunk muscles worsened with time. The stiffness was often described as board-like rigidity, especially in the trunk muscles. Ventilation became more difficult because of the deteriorating chest wall compliance caused by progressive muscular rigidity. Cognition appeared preserved; facial and extraocular movements were never impaired. Serum CK was consistently elevated, often over ten times the upper limit of normal values for age (both cardiac and skeletal muscle fractions were elevated in patient 1). The clinical similarity among all cases was complemented by a remarkable consistency in the electromyographic findings, although testing was done by at least five different electromyographers. Electromyograms were characterized by increased insertion activity and fibrillation potentials, the abnormalities becoming more marked as the condition progressed. Motor unit potentials were uniformly normal for age at the outset but the interference pattern became increasingly reduced with time. Nerve conduction velocities were normal. At least one electromyographer remarked on the absence of an EMG correlate to the muscle stiffness. Cardiac involvement is suggested by abnormal electrocardiograms and elevated CK-MB fraction in patient 1 . However, the heart muscle was normal at the time of autopsy. Experience with patient 1 led to earlier diagnosis in patients $4,5,6$, and 11 . Nine patients died before one year of age and two at 18 months. Death generally occurred from infection, inadequate gas exchange because of poor chest wall compliance, or cardiac arrest. The muscle rigidity was not influenced by neuromuscular blocking agents tested in at least three patients in whom this was assessed, and by Prednisone in one.

Neither increased insertion activity nor fibrillation potential is a specific finding on electromyography since they can be seen in disorders associated with denervation and a variety of myopathies, including inflammatory myopathies and dystrophies. ${ }^{6}$ Patients 1 and 9 were treated for inflammatory myopathies at the outset until the clinical evolution and histology excluded this diagnosis and established the unique nature of their disorder.

Several disorders can present with muscle stiffness but these can be readily distinguished clinically from the dystrophic condition herein described, although less readily in the early stages of sporadic cases. Myotonia congenita is characterized by normal CK in serum and high frequency (myotonic) discharges that typically wax and wane on needle electromyography. ${ }^{6.11}$ Such discharges were never seen in our cases. The syndrome of continuous muscle fibre activity ${ }^{7}$ generally does not present in infancy. The stiffness seen in this condition is abolished by neuromuscular blockade. Electromyogram is characterized by complex high frequency spontaneous discharges resembling motor unit potentials, occurring rhythmically and continuously. This morphology is different from myotonic discharges. $6,7.11$ Electromyographic findings in our cases did not resemble those described in Isaacs syndrome. Many authors ${ }^{8-10}$ have described familial cases with the clinical and electromyographic findings of the "stiff-man" syndrome, and Lingam et al. ${ }^{10}$ used the term "hereditary stiff-baby" syndrome to highlight the age of presentation. Serum CK was normal ${ }^{8}$ or not reported. The cases are characterized by relaxation of the muscles during sleep and with neuromuscular blockade. Electromyography typically shows persistence of normal motor unit potentials with sustained interference pattern "at rest" while awake with cessation during sleep. $8,10,11$ These were not the findings in our cases.

Ashizawa et al. ${ }^{12}$ also described a familial syndrome characterized by vermiform twitching and episodic stiffness from early childhood. Insertion activity was normal, but normal appearing motor unit potentials were observed to occur continuously and rhythmically on needle electromyography. The authors felt that the clinical and pharmacological findings in their family differed from those in previously reported cases presenting similarly, including those described as the congenital stiff-man syndrome. These clinical and electromyographic findings are different from those in our cases. Ringel et al. (1978) (13 $^{13}$ reported a neonate who was born with rigidity of all muscles, poor spontaneous movement, weak cry and serum CK levels elevated to 30 - 40 times normal. Needle electromyography was described as silent despite muscle stiffness. The stiffness improved by ten months of age. The histology was characterized by "trilaminar fibres". Thus, the clinical, electromyographic and pathological features differ from those found in our cases.

Black et al. (1972) ${ }^{14}$ described muscle stiffness occurring shortly after birth and this persisted until death at 33 days of life. Motor conduction velocity was unobtainable in the peroneal nerve. Electromyography was characterized by the occurrence of continuous activity with potentials ranging in amplitude from $50 \mu \mathrm{V}-800 \mu \mathrm{V}$ and duration of 2 to $5 \mathrm{msec}$ recurring rhythmically at $3-10 / \mathrm{sec}$. Activity continued during rest, sleep, general anesthesia, spinal anesthesia and peripheral nerve block. Muscle rigidity and electromyographic activity were abolished by tubocurarine chloride. Although the clinical and electromyographic features of this child are similar to those in our cases, this child had evidence of demyelinating and axonal neuropathy in the peripheral nerve and of denervation in skeletal muscles; there were no such findings in our cases.

Pathological hallmarks of the disease include a peculiar powdery, granular transformation of the Z-bands that appear as eosinophilic refractile granules on routine histochemistry, remotely resembling $Z$-band streaming (see above). The process seemingly begins with one sarcomere and progressively involves adjacent and neighbouring sarcomere until the entire fibre becomes a consolidated mass of amorphous granules lacking organelles and myofibrils. Phagocytosis follows and the fibre becomes an empty sarcolemmal bag. Associated findings in some but not all muscles examined have baffled rather than clarified the nature of these changes. In two cases (Patients 1 and 4), filamentous and tubular viral-like inclusions are seen within the sarcoplasm. The role of viruses has been raised in view of these findings; however, similar inclusions are reported in polymyositis and dermatomyositis. Such structures may be derived from a re-arrangement of subcellular organelles. ${ }^{15}$ Some 
cases showed nuclear inclusions in the form of paracrystalline material (Patient 9). The case also displayed cytoplasmic bodies. While these bodies have no specific significance in human disease, their relationship to the Z-band is clearly displayed by their continuity with adjacent sarcomeric Z-bands, staining density and radiating thin filaments from their periphery, somewhat similar but not identical to the granules seen in the present condition. Additionally, the granular inclusions failed to stain with nitroblue tetrazolium in the presence of menadione.

To compound the problem further, a 36-year-old male was seen at one institution (Health Sciences Centre, Winnipeg) with a clinical diagnosis of polymyositis. This man presented with progressive proximal weakness and had polyphasic potentials on EMG. A muscle biopsy showed random variation in fibre sizes with no evidence of inflammation. A few muscle fibres contained Z-band changes identical to those described here. Unfortunately, the patient was lost to follow-up three weeks later. Similar alterations were observed in two adults from England and Israel (personal communication to $\mathrm{JH}$ ).

The nature of the Z-band changes seen in this condition is unknown. Possibilities include a primary cytoskeletal defect that leads to progressive failure in the maintenance of $\mathrm{Z}$-band integrity. Candidate proteins responsible for this function could include the Z-protein, desmin, and $\alpha$-actinin. Z-band pathology encompasses a number of well-described congenital and acquired myopathic disorders with recurring morphologic Z-band abnormalities whose biochemical nature is also incompletely characterized. In the clinical context, our infants were all hypertonic or rigid; tenotomized muscle, leading to nemaline $\operatorname{rod}^{16}$ accumulation experimentally, is in a chronic state of tonic contraction. These similarities suggest that the augmented synthesis and fragmentation of Z-band material may have a common pathogenesis in the human myopathy here described and the animal model. The distribution of increased desmin in nemaline rod disease is unusual in being confined to the perinuclear and subsarcolemmal zones, ${ }^{17}$ a very similar distribution to that found in our patients with hypertonic muscular dystrophy (Figure 1C). The number of fibres with increased desmin in our patients exceeds the number of regenerating fibres; thus, regeneration alone cannot explain the excessive desmin content in these fibres.

The results of gel electrophoresis clearly show that the proband muscle is composed of a different profile of proteins than normal age-matched muscle. Bands that changed in density were either more or newly evident ( 54 and $10 \mathrm{kDa}$ respectively) or less apparent $(100,80,42$, and $22-24 \mathrm{kDa})$. Identification of these bands without Western blots, 2-dimension electrophoresis, ${ }^{18}$ 3 -dimension localization, ${ }^{19}$ or dissolution of $\alpha$-actinin using calpain $^{20}$ is not certain. However, a major actin-binding protein is $\alpha$-actinin, a Z-disc protein, which co-migrates to $100 \mathrm{kDa}$. Substantial loss of $\alpha$-actinin from skeletal proband muscle (no abnormalities were noted in cardiac muscle ultrastructure) would likely alter Z-disc appearance and muscle function. ${ }^{21}$ Such a defect was reported in site-directed mutagenesis on fliA3 $\alpha$-actinin mutants and resulted in disrupted, punctate $\mathrm{Z}$ discs and loss of the integrity of myofibrillar attachments. ${ }^{22} \mathrm{~A}$ band at the molecular weight of actin and of severin $(42 \mathrm{kD})$, which severs and caps actin and nucleates actin assembly, was also less apparent in the proband than in normal muscle.
The $80 \mathrm{kD}$ band was also reduced in the proband muscle. Both calpain, a $\mathrm{Ca}^{2+}$-dependent protease that may be cleaved by SDS to 34,46 , and $70 \mathrm{kD}$ fragments, ${ }^{23}$ and protein 4.1 that binds actin and spectrin ${ }^{24}$ would migrate to the $80 \mathrm{kD}$ position. The $54 \mathrm{kDa}$ band in the proband muscle may include increased amounts of vimentin ${ }^{25.26}$ associated with desmin at Z-lines. ${ }^{27}$ Alternatively, a $55 \mathrm{kDa}$ actin-bundling protein may be involved. ${ }^{28}$ The $10 \mathrm{kDa}$ band may be breakdown products of proteins, damaged because of myofibrillar disruption but is not likely since an aberrant short or degraded form of $\alpha$-actinin could also appear as a $10 \mathrm{kDa}$ band, although experiments with disrupted $\alpha$-actinin, ${ }^{22.29}$ suggest that a lethal condition would require absence rather than expression of truncated forms of the protein. ${ }^{21.30}$ It is interesting to speculate, however, on a possible involvement of skeletal muscle-specific $\alpha$-actinin (ACTN3) which is distinct from the cardiac $\alpha$-actinin and is encoded on chromosome $11 \mathrm{q} 13-\mathrm{q} 14 .{ }^{31}$ The defect is not likely to be the same as that identified by Laing ${ }^{32}$ for autosomal dominant nemaline myopathy (NEM1-MIM \#161800) on chromosome 1, which excluded the skeletal muscle $\alpha$-actinin gene. Further studies will be undertaken to find out if the protein alterations seen in this disease are different from those of other childhood muscle disorders.

The clinical, electromyographic and pathologic findings in our cases do not resemble those described with any specific form of malignant hyperthermia; however, we cannot exclude a predisposition to this phenomenon because none of these infants had anesthetic exposure during their course. The clinical presentation and electromyographic findings in our cases are not those of tetanus.

There were no electromyographic correlates to the muscle stiffness/rigidity in our cases. Persistence of the stiffness after neuromuscular blockade suggests a disturbance in the muscle as does the marked elevation in the muscle fraction of the serum $\mathrm{CK}$ and the pathological changes found in skeletal muscle. We speculate that the stiffness/rigidity may be due to disturbance of the myofilaments particularly at the region of the Z-bands. The skeletal muscle in at least one case was dystrophin positive. Other than this, we have not characterized the membrane and/or ionic characteristics of the muscle fibres in our patients.

Autosomal recessive inheritance is the most likely mode of transmission for this disorder. This is supported by equal sex involvement ( 5 males, 5 females), multiply-affected siblings, clinically and biochemically normal parents and consanguinity in 3 families from isolated inbred communities. All involved aboriginal infants are of Cree ancestry.

We suggest that the disorder reported herein represents an undescribed myopathy which qualifies as a dystrophy because of its progressive nature, consistently marked elevation of the serum $\mathrm{CK}$, and the pathologic features of necrosis, regeneration, and fibrosis, normal motor NCV's, and absent systemic metabolic disturbances.

\section{REFERENCES}

1. Dudley MA, Dudley AW Jr, Bernstein LM, Hoogstraten J, Trevenen C. Progressive neonatal rigidity: biochemical aspects of a new familial myopathy. J Neuropathol Exp Neurol 1979; vol: 311 .

2. Trevenen CL, Hoogstraten J, DeGroot W, Seshia SS. Progressive muscular rigidity with respiratory failure in infancy: a new myopathy. Can J Neurol Sci; August 1979, 6: 379 (abstract). 
3. Dudley AW. Progressive neonatal rigidity. In: Kakulas $\mathrm{V}$ and Adams R, eds. Diseases of Muscle. Harper and Row, 1985: 328-331.

4. Hames BD and Rickwood, D. One-dimensional polyacrylamide gel electrophoresis. In: Hames BD and Rickwood D, eds. Gel Electrophoresis of Proteins, a Practical Approach, second edition. New York, IRL Press at Oxford University Press, 1990; 1139.

5. Laemmli UK. Cleavage of structural proteins during the assembly of the head of bacteriophage T4. Nature 1970; 227: 680-685.

6. Kimura J. Electrodiagnosis. In: Diseases of Nerve and Muscle: Principles and Practice. Edition 2. Philadelphia: F.A. Davis Company, 1989: 258-259.

7. Isaacs $\mathrm{H}$. Continuous muscle fibre activity in an indian male with additional evidence of terminal motor fibre abnormality. J Neurol Neurosurg Psychiatry 1967; 30: 126-133.

8. Klein R, Haddon JE, DeLuca C. Familial congenital disorder resembling stiff man syndrome. Am J Dis Child 1972; 124: 730731.

9. Sander JE, Layzer RB, Goldsobel AB. Congenital stiff man syndrome. Ann Neurol 1980; 8: 195-197.

10. Lingam S, Wilson J, Hart EW. Hereditary stiff baby syndrome. Am J Dis Child 1981; 135: 909-911.

11. Barwick DD and Fawcett PRW. The clinical physiology of neuromuscular disease. In: Sir John Walton, ed. Disorders of Voluntary Muscle, 5th edition. Churchill Livingstone, 1988: 1015-1080.

12. Ashizawa T, Butler IJ, Harati Y, Roongta SM. A dominantly inherited syndrome with continuous motor neuron discharges. Ann Neurol 1983; 13: 285-290.

13. Ringel SP, Neville HE, Duster MD, and Carroll JE. A new congenital neuromuscular disease with trilaminar fibers. Neurology 1978; 28: 282-289.

14. Black JT, Garcia-Mullin R, Good E, Brown S. Muscle rigidity in a newborn due to continuous peripheral nerve hyperreactivity. Arch Neurol 1972; 27: 413-425.

15. Chou SM. Myxovirus-like structures in a case of chronic polymyositis. Science $1967 ; 158: 1453$.

16. Karpati G, Carpenter S, Eisen AA. Experimental core-like lesions and nemaline rods: a correlative morphological and physiological study. Arch Neurol 1972; 27: 237-251.

17. Sarnat HB. Vimentin and desmin in maturing skeletal muscle and developmental myopathies. Neurology 1992; 42: 1616-1624.

18. Hashimoto K, Shimizu T, Nonaka I, Mannen T. Immunochemical analysis of $\alpha$-actinin of nemaline myopathy after two-dimensional electrophoresis. J Neurol Sci 1989; 93: 199-209.
19. Isobe Y, Warner FD, Lemanski LF. Three-dimensional immunogold localization of $\alpha$-actinin within the cytoskeletal networks of cultured cardiac muscle and non-muscle cells. Proc Natl Acad Sci USA 1988; 85: 6758-6762.

20. Goll DE, Dayton WR, Singh I, Robson RM. Studies of the $\alpha$ actinin/actin interaction in the Z-disk using calpain. J Biol Chem 1991; 266: 8501-8510.

21. Blanchard A, Ohanian V, Critchley D. The structure and function of $\alpha$-actinin. J Muscle Res Cell Motil 1989; 10: 280-289.

22. Fyrberg E, Kelly M, Ball E, Fyrberg C, Reedy MC. Molecular genetics of Drosophila $\alpha$-actinin: mutant alleles disrupt Z-disc integrity and muscle insertions. J Cell Biol 1990; 110 : 1999. 2011.

23. Kapprell $\mathrm{H}$, Goll DE. Effect of $\mathrm{Ca}^{2+}$ on binding of the calpains to calpastatin. J Biol Chem 1989; 264: 17888-17896.

24. Tanaka T, Kadowaki K, Lazarides E, Sobue K. $\mathrm{Ca}^{2+}$-dependent regulation of the spectrin/actin interaction by calmodulin and protein 4.1. J Biol Chem 1991; 266: 1134-1140.

25. Granger BL, Repasky EA, Lazarides E. Synemin and vimentin are components of intermediate filaments in avian erythrocytes. $\mathrm{J}$ Cell Biol 1982 ; 92: 299-312.

26. Gard DL, Lazarides E. Specific fluorescent labelling of chicken myofibril Z-line proteins catalyzed by guinea pig liver transglutaminase. J Cell Biol 1979; 81: 336-347.

27. Cossette LJ, Vincent M. Expression of a developmentally regulated cross-linking intermediate filament associated protein (IFA Pa400) during the replacement of vimentin for desmin in muscle cell differentiation. J Cell Science 1991; 98(2): 251-260.

28. Yamashiro-Matsumura S, Matsumura F. Intracellular localization of the 55-kD actin-bundling protein in cultured cells: spatial relationships with actin, $\alpha$-actinin, tropomyosin, and fimbrin. J Cell Biol 1986; 103: 631-640.

29. Schleicher M, Noegel A, Schwarz T, et al. A Dictyostelium mutant with severe defects in $\mu$-actinin: its characterization using cDNA probes and monoclonal antibodies. J Cell Sci 1988; 90: 59-71.

30. Matsudaira $P$. Modular organization of actin crosslinking proteins. Trends Biol Sci 1991; 16: 87-92.

31. Beggs AH, Byers TJ, Knoll JHM, et al. Cloning and characterization of two human skeletal muscle $\alpha$-actinin genes located on chromosomes 1 and 11. J Biol Chem 1992; 267(13): 9281-9288.

32. Laing NG, Majda BT, Akkari PA, et al. Assignment of a gene (NEM1) for autosomal dominant nemaline myopathy (MIM \#161800) to chromosome 1. Am J Hum Genet 1992; 50: 576583. 